\title{
Remodelación de los colgajos TRAM libres y DIEP
}

\section{Reshaping in free TRAM and DIEP flaps}

\author{
Fidalgo Rodríguez, F.*, Redondo Camacho, A.*, Dean Ferrer, A.**, Rioja Torrejón, L. F.***
}

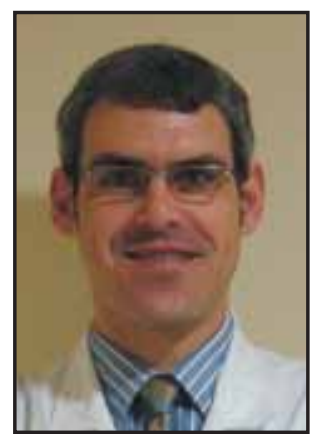

Fidalgo Rodríguez, $\mathrm{F}$.

\section{Resumen}

La reconstrucción mamaria mediante autotrasplante microquirúrgico es la técnica de elección en la mayoría de las pacientes mastectomizadas. Los avances técnicos han permitido el desarrollo del colgajo TRAM libre y posteriormente del Colgajo DIEP como exponentes más representativos del arsenal terapéutico en este campo.

Para los cirujanos reconstructores la práctica de estas intervenciones supone un auténtico reto; un reto que ha de convertirse en el quehacer diario de los Servicios de Cirugía Plástica y Reconstructiva, si quieren adaptarse a los tiempos modernos.

En nuestro Servicio estas técnicas comienzan a aplicarse en 1999 y desde entonces se han llevado a cabo en 42 casos. Al principio se prestaba mayor atención al desarrollo del proceso microquirúrgico y el cirujano centraba su esfuerzo en la consecución de una sutura óptima que asegurara la supervivencia del colgajo. Una vez conseguido esto, lo demás se consideraba secundario. No obstante nuestra concepción ha cambiado y actualmente centramos el proceso no sólo en lo anterior, sino en la remodelación adecuada del colgajo para dotar a la mama de un aspecto verdaderamente auténtico.

En el presente trabajo se exponen una serie de consejos que pueden ser útiles a la hora de concluir la reconstrucción mamaria mediante TRAM libre o DIEP confeccionando una mama de contorno natural, lo más parecida posible a la mama contralateral. Concluimos que en este matiz se encuentra el verdadero éxito de la reconstrucción mamaria.

Palabras clave Remodelación. Mama. Reconstrucción.

Código numérico 5214-52140
Breast reconstruction through microsurgical autotrasplant is the most common procedure in breast cancer patients. The technical advances have allowed the development of the free TRAM flap (later the DIEP flap), which are the prime examples of the therapeutic material in this field.

The implementation of microsurgical techniques has improved the results in breast reconstruction by increasing the survival rate and decreasing the complications.

For plastic surgeons, the practice of this procedure is a genuine challenge which, nowadays, should become a daily task in all Plastic Surgery Units.

In our Plastic Surgery Unit, the implementation of these techniques started in 1999, having practiced 42 cases so far. At first, the development of the microsuture was the most important issue; every surgeon's effort was directed to achieve an optimal suture. The rest was considered of lesser importance.

However, our conception has changed: we consider that the most important issue now is not only the effort mentioned above but, mainly, a satisfactory reshaping of the flap in order to give the breast an actual appearance.

In the present study, we put forward a series of technical advices that can be useful when finishing breast reconstruction through either free TRAM or DIEP, recreating a new breast as similar to the counterside healthy breast as possible.

We show up, then, the importance of this fact in order to achieve a successful breast reconstruction.

Key words Remodelation. Breast Reconstruction.

Numeral Gode $\quad 5214-52140$ 


\section{Introducción}

La reconstrucción mamaria mediante autotrasplante microquirúrgico puede realizarse empleando diferentes tipos de colgajos. Los que ofrecen mejores resultados son los que aprovechan el exceso de tejido del abdomen. Inicialmente se usó el colgajo TRAM libre $(1,2)$, más tarde se evolucionó hacia los colgajos TRAM con conservación de músculo y posteriormente se produjo la evolución hacia el colgajo DIEP. En cualquiera de los casos el objetivo es el mismo: reproducir con la mayor fidelidad posible las características propias de la mama.

Entre las principales indicaciones para la reconstrucción mamaria mediante este método podemos enunciar las siguientes: tórax irradiado, con signos de radiodermitis crónica o con importante retracción cicatricial; imposibilidad para el uso de otros colgajos como el de Dorsal Ancho; mama contralateral ancha o hipertrófica; negativa expresa de la paciente al
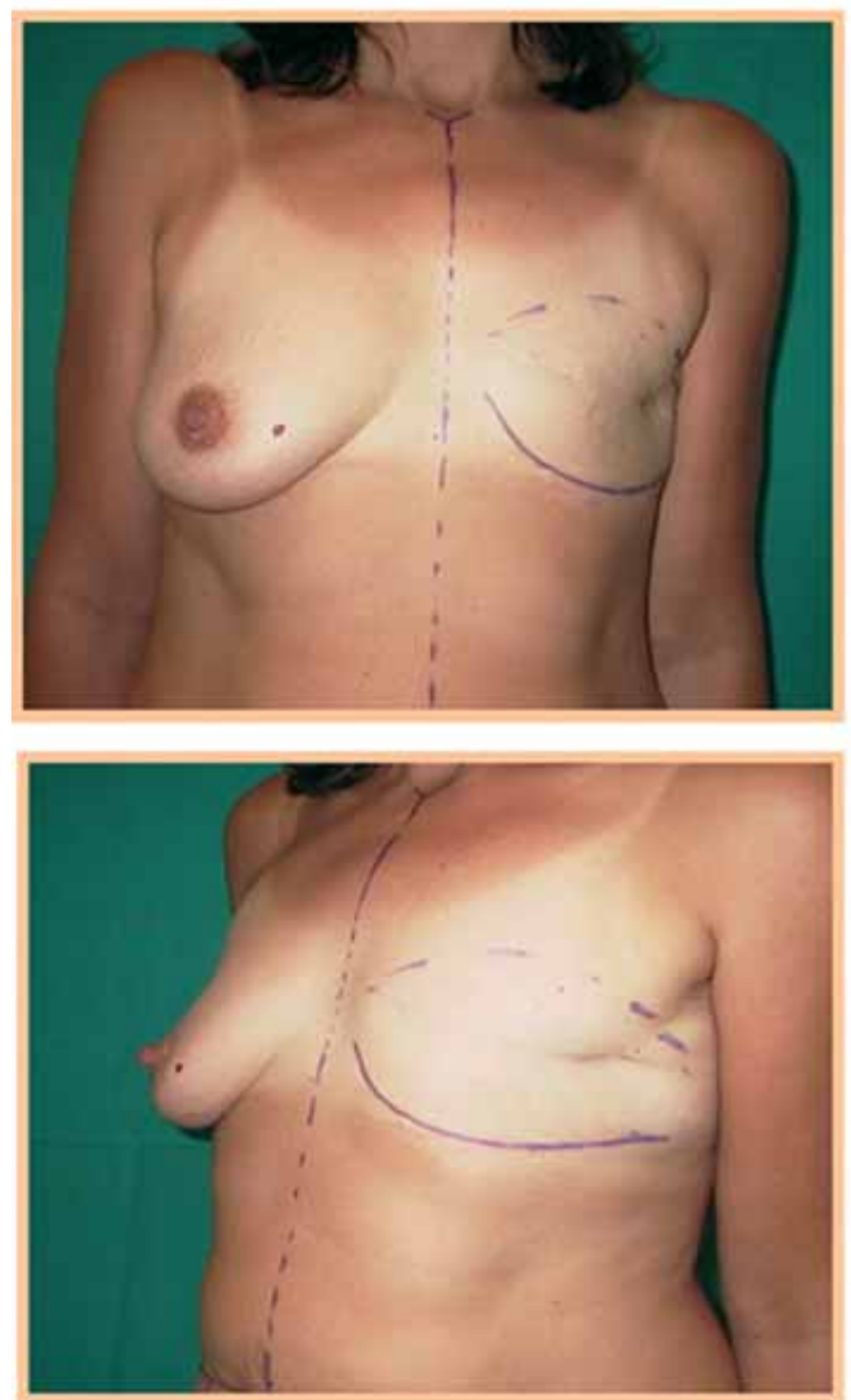

implante de prótesis de silicona y deseos de la paciente de ser reconstruida mediante estas técnicas.

La revisión de la bibliografía existente (3-6), en la que queda reflejada la experiencia de autores de reconocido prestigio internacional, pone de manifiesto que la reconstrucción mediante autotrasplante microquirúrgico, al principio con TRAM libre y actualmente con DIEP $(7,8)$, es la opción reconstructiva de elección en la mujer mastectomizada, a veces con independencia de las indicaciones anteriores.

Esta preferencia se debe a las grandes ventajas que se obtienen cuando se aplican estas técnicas, siempre de acuerdo con una selección adecuada de las pacientes y con la realización correcta de las mismas $(9,10)$.

La adquisición de experiencia en este campo ha permitido mejorar los tiempos quirúrgicos, procediendo a la extracción de los colgajos y a la realización de las microsuturas en tiempos cada vez más reducidos, con índices de complicaciones muy bajos y con resultados muy aceptables.
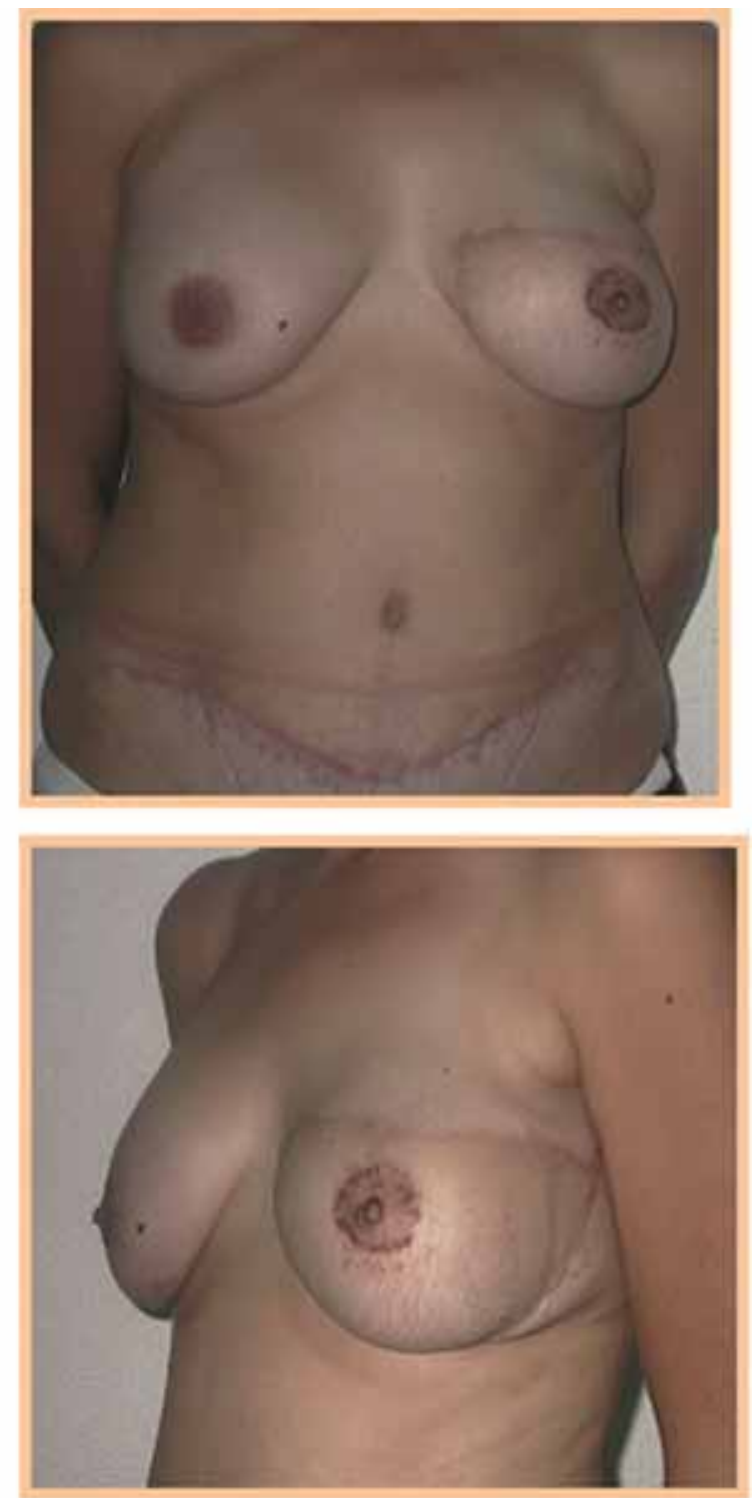

Fig. 1. Reconstrucción mamaria diferida en paciente de 42 años: TRAM libre. Preoperatorio y postoperatorio al año. 

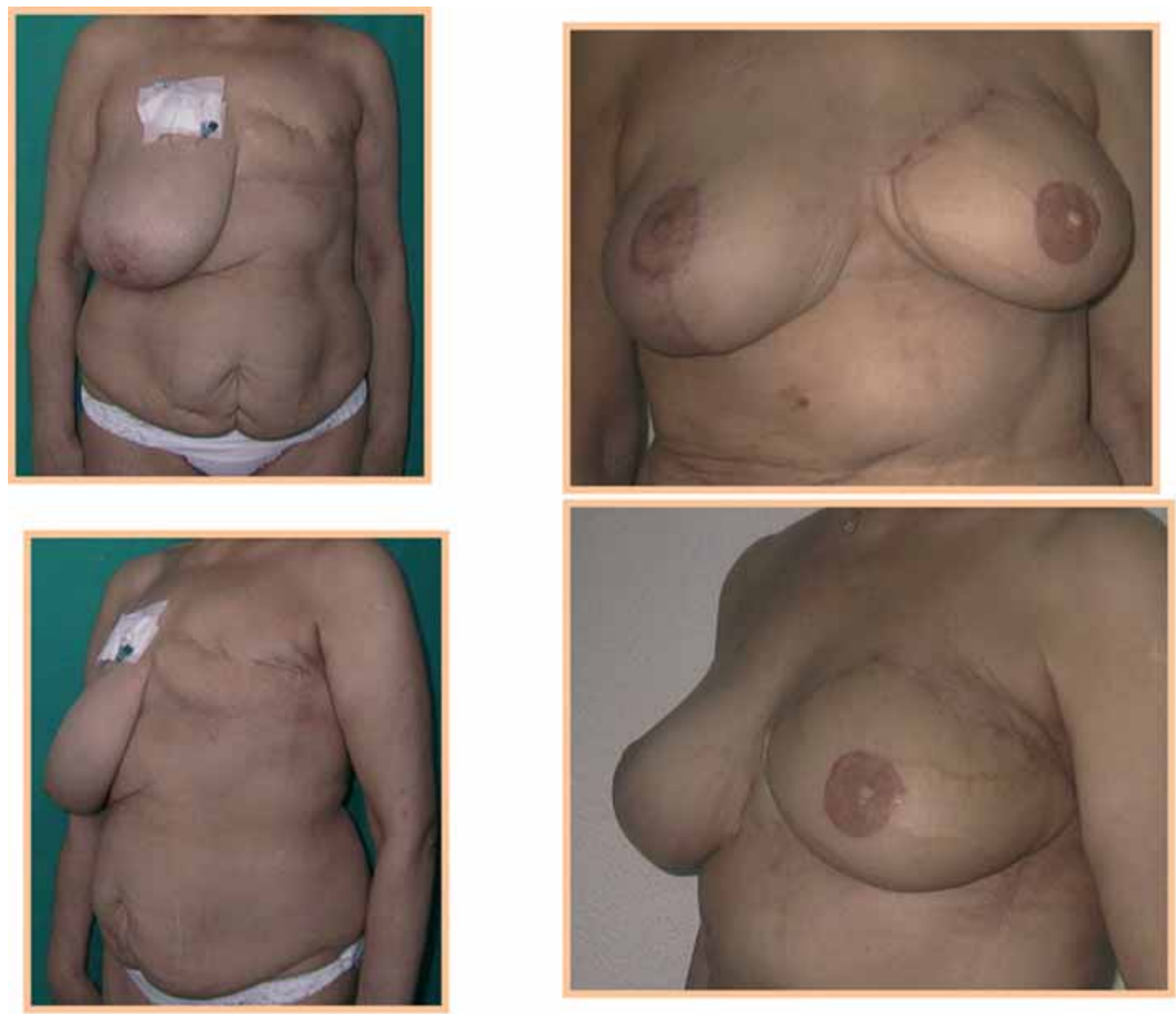

Fig. 2. Reconstrucción mamaria diferida en paciente de 62 años: TRAM libre. Preoperatorio y postoperatoria al año.

No obstante, una vez superado el reto de la técnica y habiendo obtenido una experiencia de incalculable valor en el ámbito de la reconstrucción microquirúrgica, la remodelación del colgajo es la que adquiere, si cabe, un valor mayor y unos matices más sutiles. La construcción de una mama requiere la consideración de varios elementos específicos que la conforman y que le dan su aspecto característico y natural, como son la cola mamaria, el surco submamario, la ptosis mamaria adecuada o la posición del complejo teloareolar.

En el presente trabajo pretendemos exponer una serie de procedimientos prácticos que pueden ser de utilidad en éste, que consideramos, es un aspecto crucial: la remodelación de los colgajos TRAM y DIEP.

\section{Material y método}

El presente trabajo está basado en la observación de los resultados de la práctica de diferentes procedimientos quirúrgicos sobre los primeros 50 colgajos TRAM libres y DIEP, una vez realizada la microanastomosis en el sito receptor, con el objetivo de reproducir lo más fielmente posible las características de una mama normal.

La técnica reconstructiva aplicada fue inicialmente el colgajo TRAM libre y posteriormente el colgajo DIEP.

Después de un postoperatorio mínimo de 6 meses, las pacientes fueron programadas para la realización de cirugía adicional sobre la mama contralateral, generalmente consistente en reducción-elevación de la mama y reconstrucción del complejo teloareolar mediante colgajo local para el pezón e injerto de piel de espesor total extraído de la cara interna del muslo para la areola. El complejo fue situado en posición, intentando conseguir la mayor simetría con la mama 

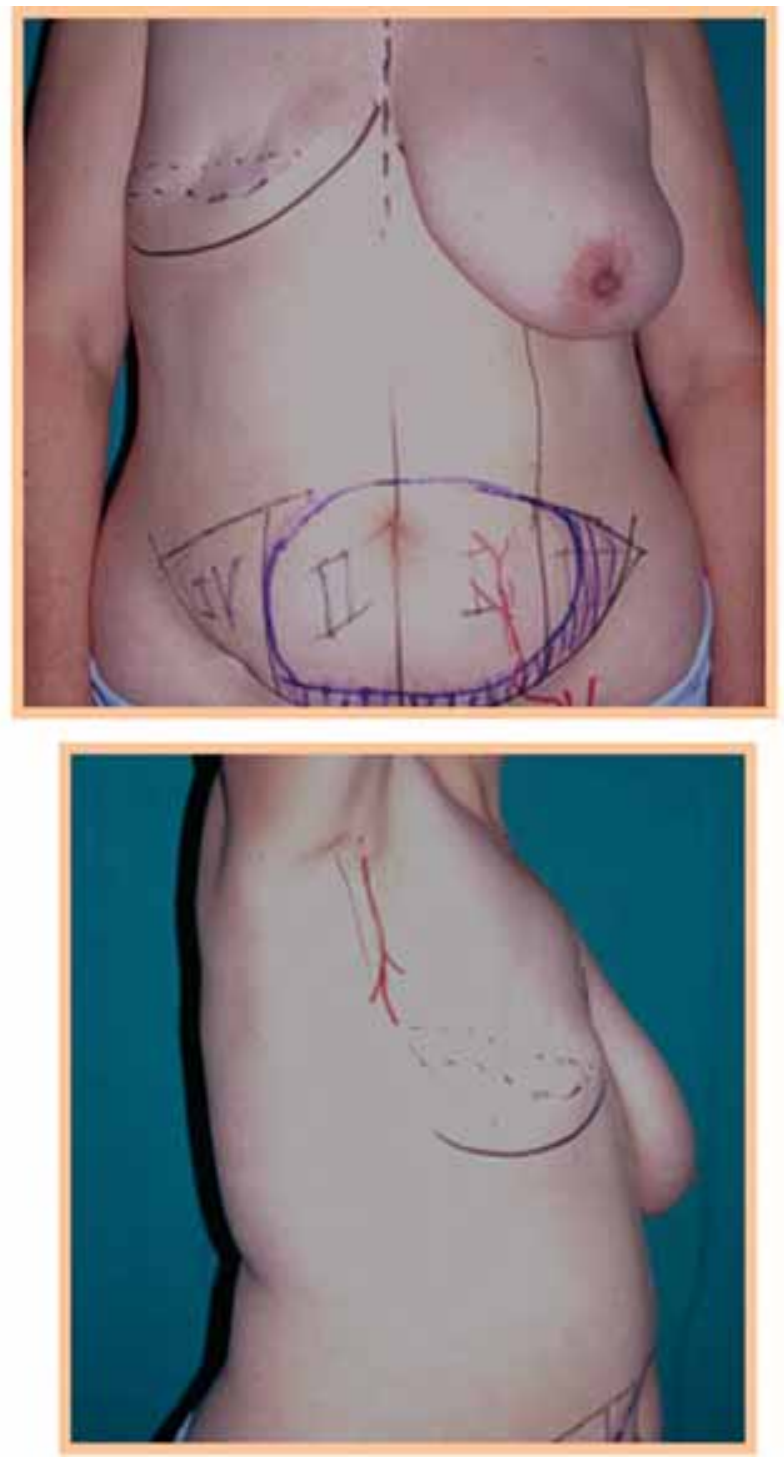
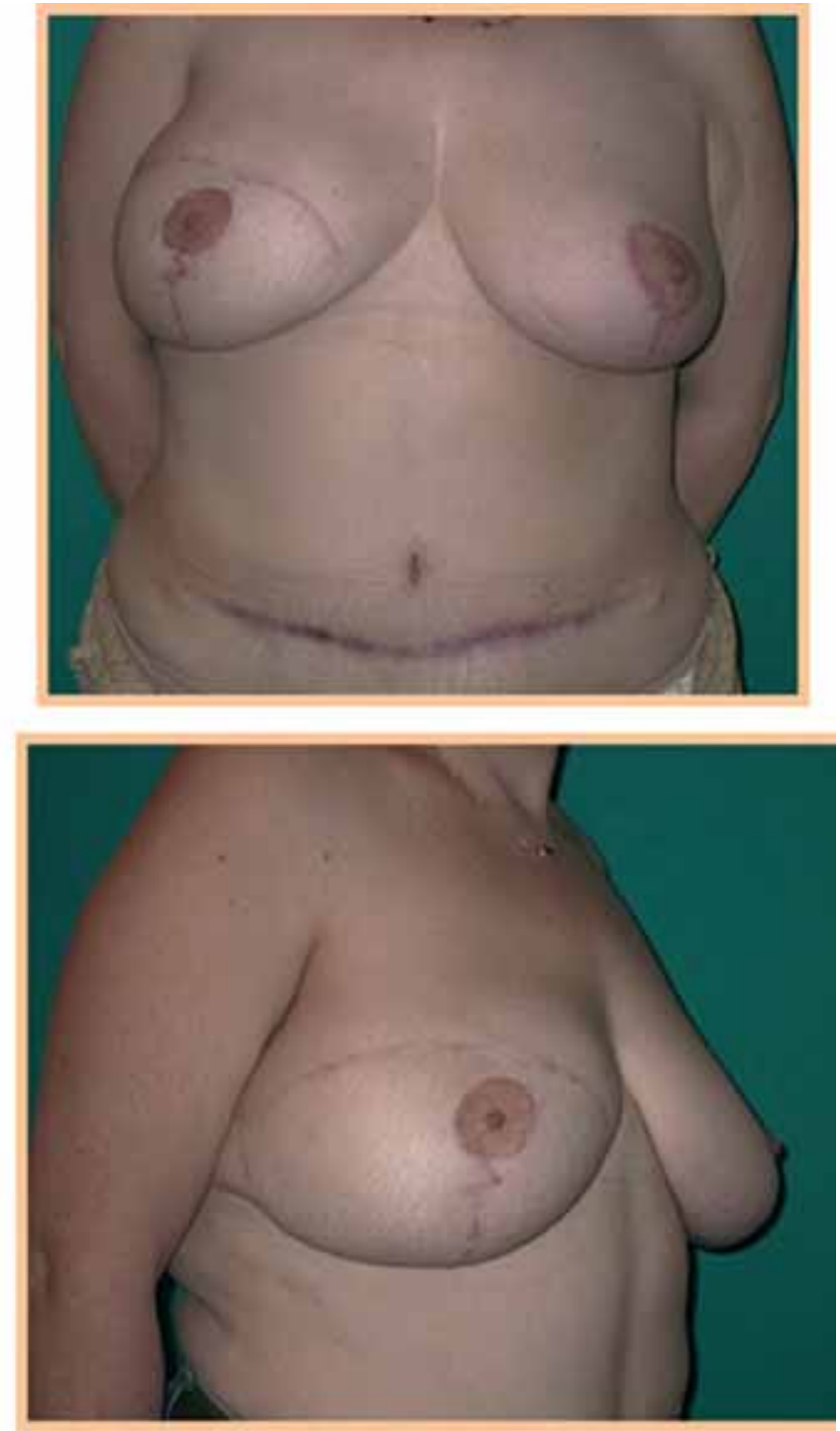

Fig. 3. Reconstrucción mamaria diferida en paciente de 56 años: DIEP. Preoperatorio y postoperatorio al año. Nota: en este caso el colgajo se talló con pedículo contralateral.

contralateral, pero con frecuencia se permitieron ligeras diferencias para conseguir un mayor equilibrio en la mama reconstruida, centrando el nuevo complejo en la mama independientemente de las medidas tomadas con respecto a la mama contraria. El proceso reconstructivo total duro una media de 16 meses

\section{Resultados}

Desde el año 1999 hasta el 2004 se ha realizado en nuestro Servicio de Cirugía Plástica y Reparadora del Hospital Reina Sofía de Córdoba, España, un total de 50 reconstrucciones mamarias mediante autotrasplante microquirúrgico. De ellas 24 fueron realizadas mediante TRAM libre y 26 mediante DIEP (Fig. 1-4).

La edad media de las pacientes fue de 43,6 años, con un rango comprendido entre los 34 y los 70 años.

Todas las reconstrucciones fueron diferidas, con un intervalo medio de tiempo transcurrido entre la mas- tectomía y la reconstrucción de 3,96 años. Todas las pacientes habían sido sometidas a mastectomía radical modificada con cicatriz horizontal cuando no fue precisa disección axilar, o ligeramente oblicua cuando fue indicada la linfadenectomía. Estos tratamientos fueron realizados en el Servicio de Cirugía General.

Un 78\% de las pacientes fueron sometidas a radioterapia postoperatoria con signos de radiodermitis cutánea moderada o leve; tan solo 5 de los casos presentaron trastornos tróficos relevantes en la piel torácica. El resto de las pacientes no precisó radioterapia. La zona donante del colgajo no presentaba signos que contraindicasen su uso en ninguna de las pacientes, tales como cicatrices de laparotomía media infraumbilical o hernias abdominales En las pacientes se constató un índice de masa corporal medio del $27 \%$. Este ligero sobrepeso nos proporcionaba suficiente redundancia de tejido dermograso abdominal: el grosor medio del panículo adiposo del colgajo fue de $3,3+/-1.2 \mathrm{~cm}$ 

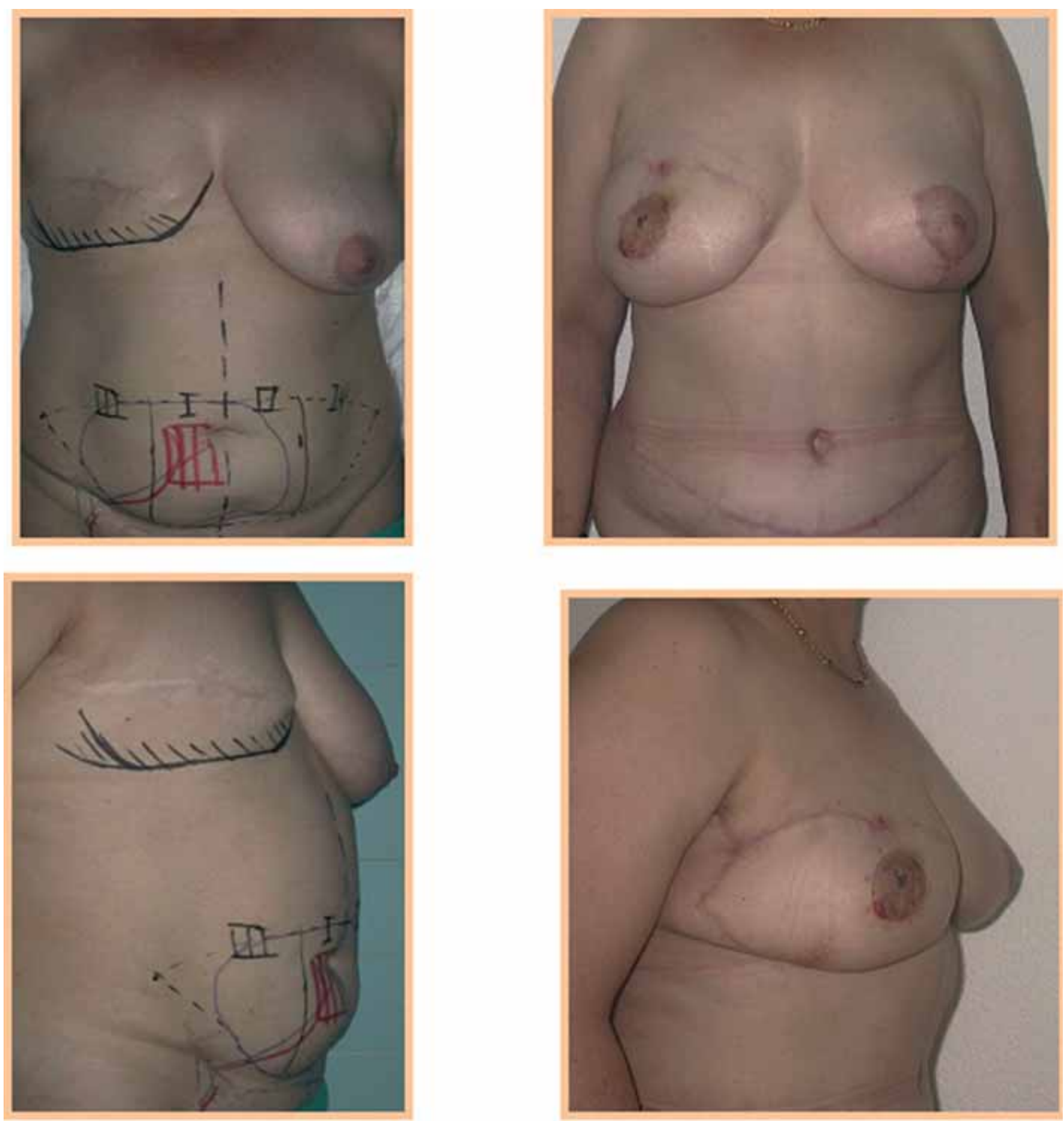

Fig. 4. Reconstrucción mamaria diferida en paciente de 48 años: DIEP. Preoperatorio y postoperatorio a los 4 meses.

Tres de las pacientes fueron sometidas a reconstrucción mamaria bilateral en el mismo acto quirúrgico, mientras que el resto fue objeto de reconstrucción unilateral.

Como complicaciones, se produjeron dos perdidas totales (ambas de colgajos TRAM) y cuatro perdidas parciales del colgajo que afectaron sobre todo a la zona III. En las primeras se optó por técnicas alternativas como el colgajo de dorsal ancho y en las últimas, se remodeló el resto del colgajo de forma aceptable.
Con la aplicación de los detalles técnicos descritos en este trabajo se han obtenido mamas reconstruidas con un alto grado de similitud con una mama natural. La morfología de la mama original normalmente no era reproducida, pero la forma y el volumen de la mama resultante permitían adecuar el volumen de la mama sana mediante técnicas de reducción-mastopexia y conseguir simetría en un porcentaje elevado. La valoración que las pacientes hicieron del resultado de la reconstrucción fue en la mayor parte de los casos muy buena, como revelaron las entrevistas a las que 


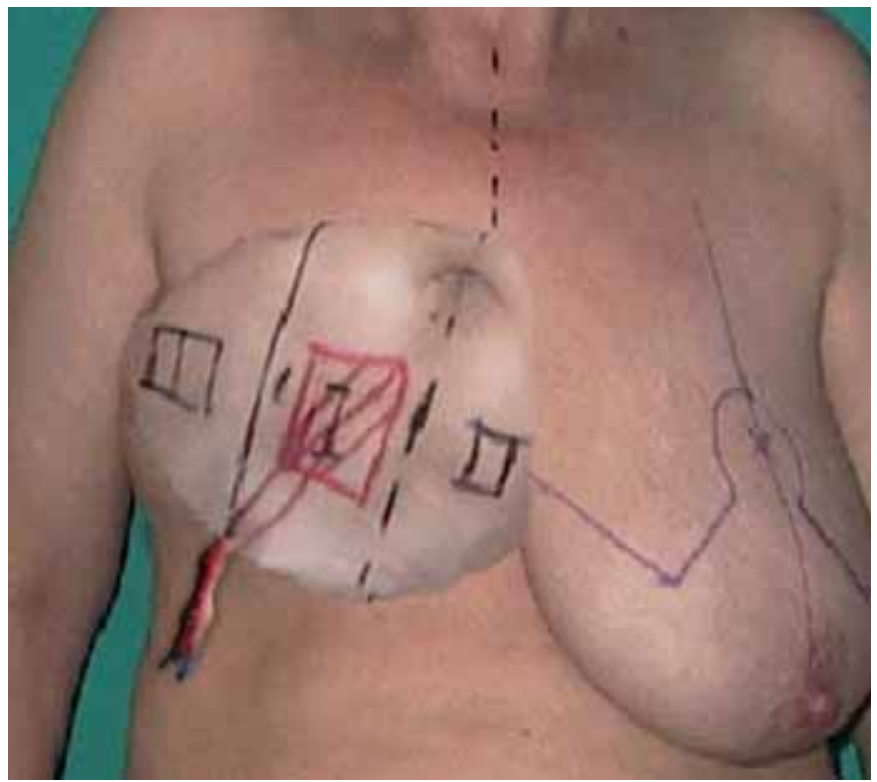

Fig. 5. Imagen del defecto en el tórax de la paciente y diseño preoperatorio de un TRAM

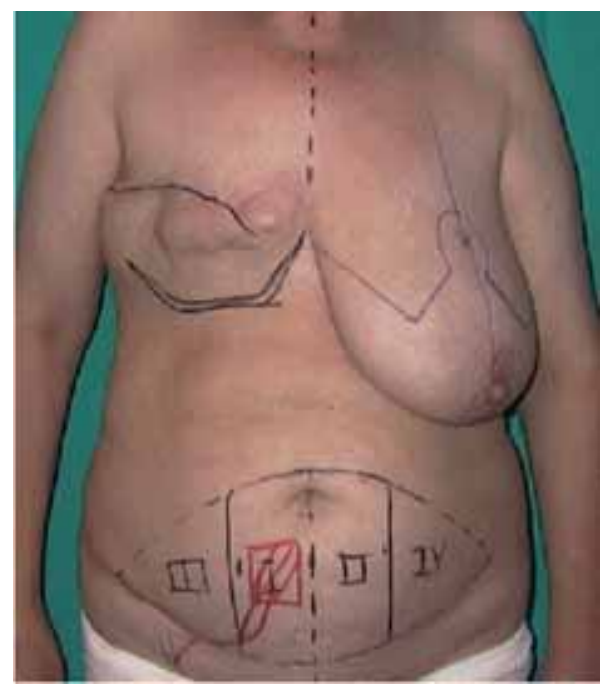

Fig. 7. Esquema en el que se muestra la posición del ombligo en la zona receptora.

fueron sometidas. La simetría mamaria fue bien valorada por la mayor parte de las pacientes al igual que el volumen y la forma.

Sin embargo las cicatrices abdominales y la apariencia del Complejo teloareolar, con frecuencia de tonalidad diferente al de la mama sana y con escasa proyección del pezón, fueron peor valorados por un tercio aproximadamente de las pacientes. En conjunto, alrededor del $85 \%$ de las pacientes consideraron restaurada de forma adecuada su integridad corporal. Estos datos han sido recogidos y analizados mediante un protocolo de recogida de impresiones subjetivas que también hemos publicado recientemente (11).

Con sencillas maniobras y un adecuado diseño, se ha logrado conformar mamas de aspecto natural con adecuada ptosis, con similar disposición de los volú-

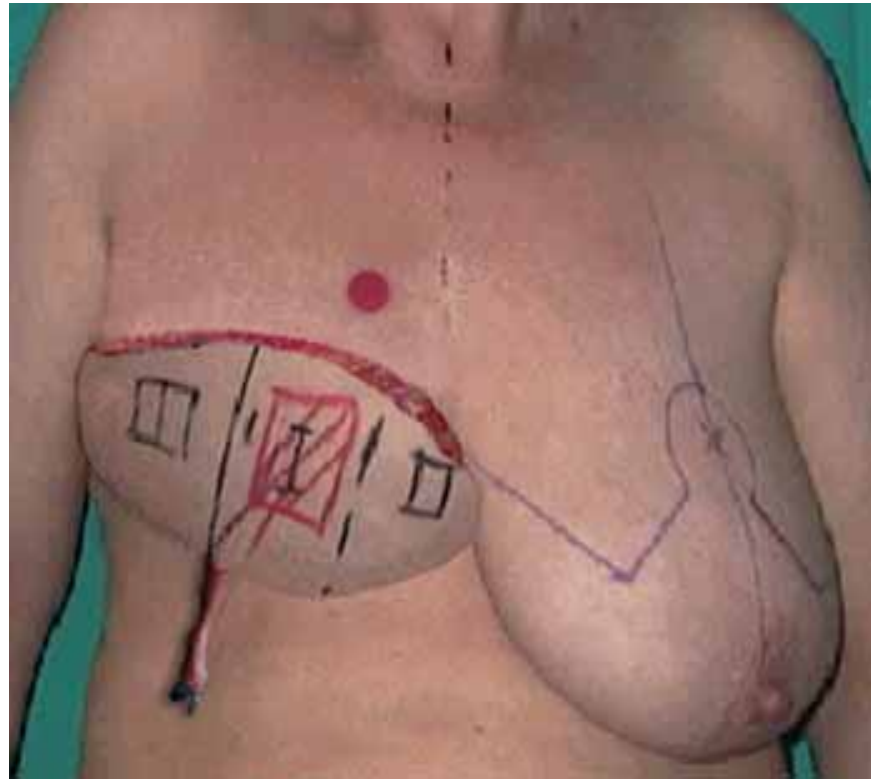

Fig. 6. Esquema de la posición relativa del colgajo en el tórax una vez extraído. Nótese la situación de la zona III y las áreas del colgajo que se aprovechan.

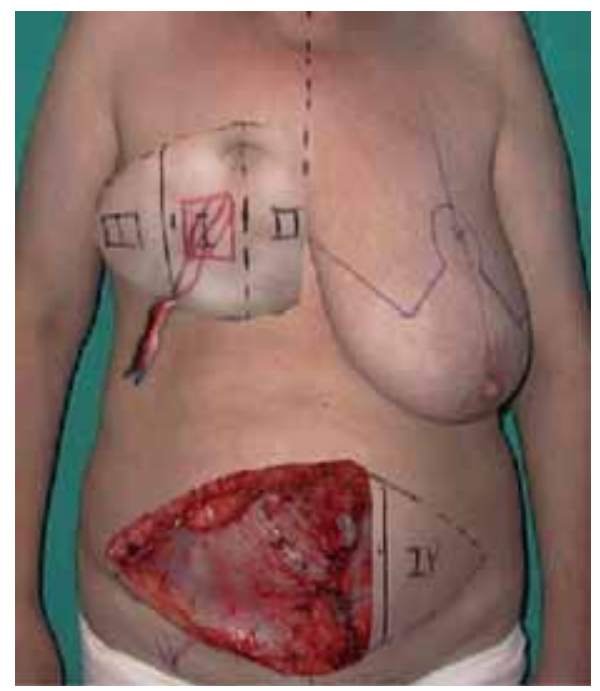

Fig. 8. Representación del colgajo oculto tras el colgajo torácico superior. Nótese la posición del ombligo que queda oculto.

menes de los cuadrantes, incluyendo la reproducción de la cola mamaria y con camuflaje a veces muy eficaz de las cicatrices umbilicales. Todo ello con las ventajas de usar tejidos autólogos.

\section{Discusión}

Cuando nos planteamos los objetivos de la reconstrucción mamaria mediante colgajos TRAM libre o DIEP consideramos los siguientes puntos:

Reconstruir la mama con tejido autólogo: ofrece notables ventajas funcionales y estéticas que influirán en la calidad de vida de la paciente y evitarán además el uso de implantes protésicos, con los inconvenientes que estos conllevan.

-Conseguir una mayor maleabilidad del colgajo en 


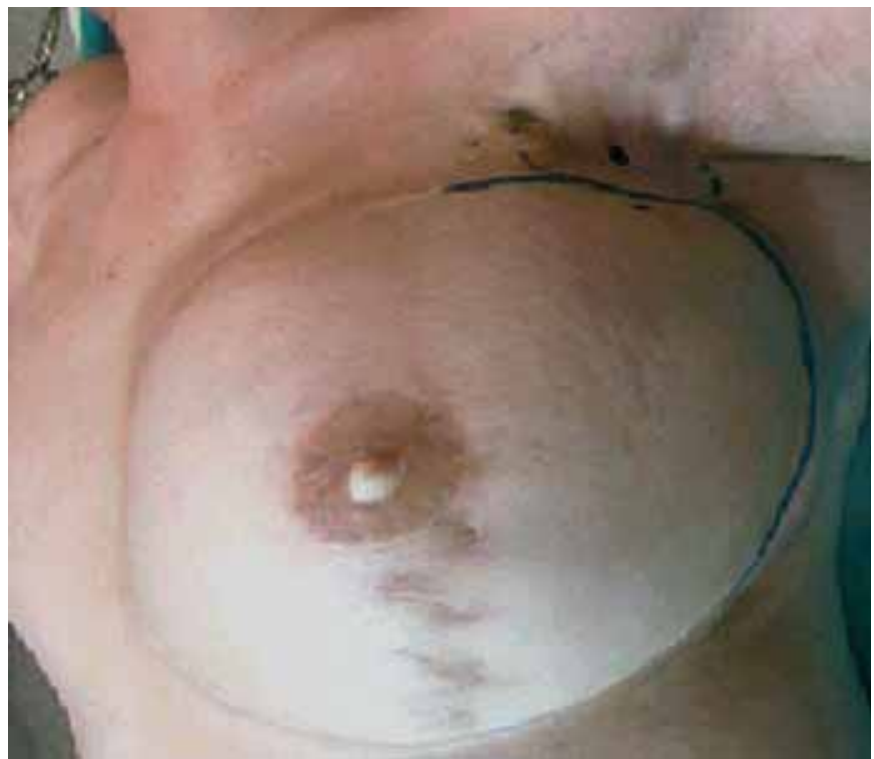

Fig. 9. Z-plastias en polo inferior.

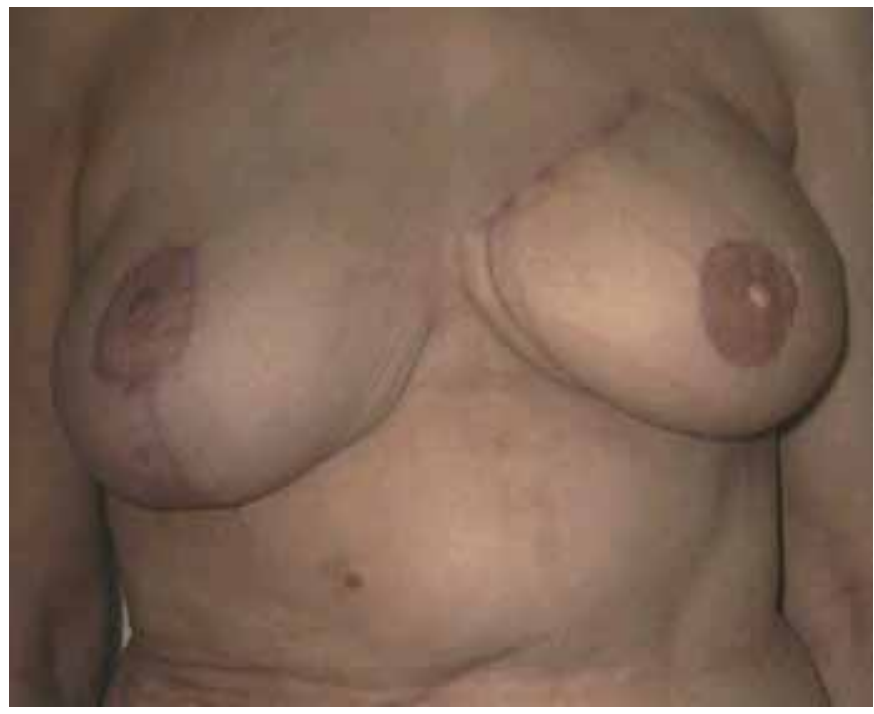

Fig. 11. Esquema en el que se muestra la posición del surco submamario y de la porción de piel torácica que se reseca para dar cabida al colgajo. Visión frontal.

lo que se refiere a su remodelación, orientación y acomodación en el sitio receptor.

-Favorecer un mayor aporte sanguíneo del colgajo proporcionado por el pedículo epigástrico inferior, que como sabemos es de mayor calibre que el superior; además se "captura" el angiosoma primario que es el de la zona homolateral, con lo que los flujos se optimizan $(12,13)$.

-Inducir con esto un menor índice de necrosis grasa y evitar la repercusión que ésta tiene en el volumen de la mama reconstruida.

-Finalmente, consecuencia de todo lo anterior, obtener el mejor resultado estético posible, sin disminuir la fiabilidad del colgajo.

Partimos de la premisa de que la reconstrucción mamaria postmastectomía por cáncer de mama es la culminación de un proceso integral de tratamiento de

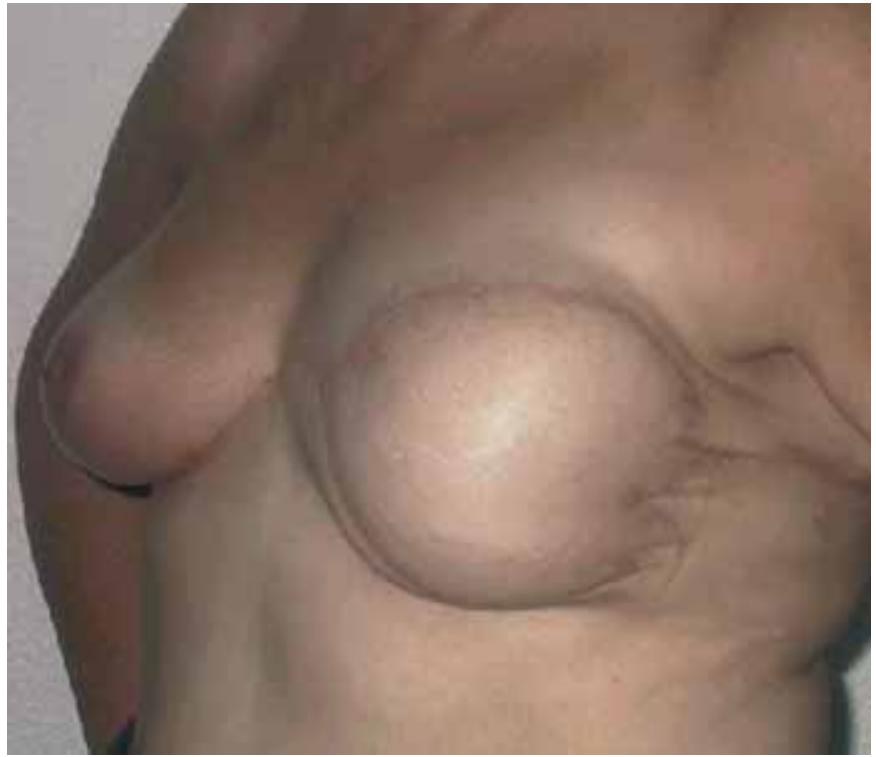

Fig. 10. Z-plastias en cola de la mama.

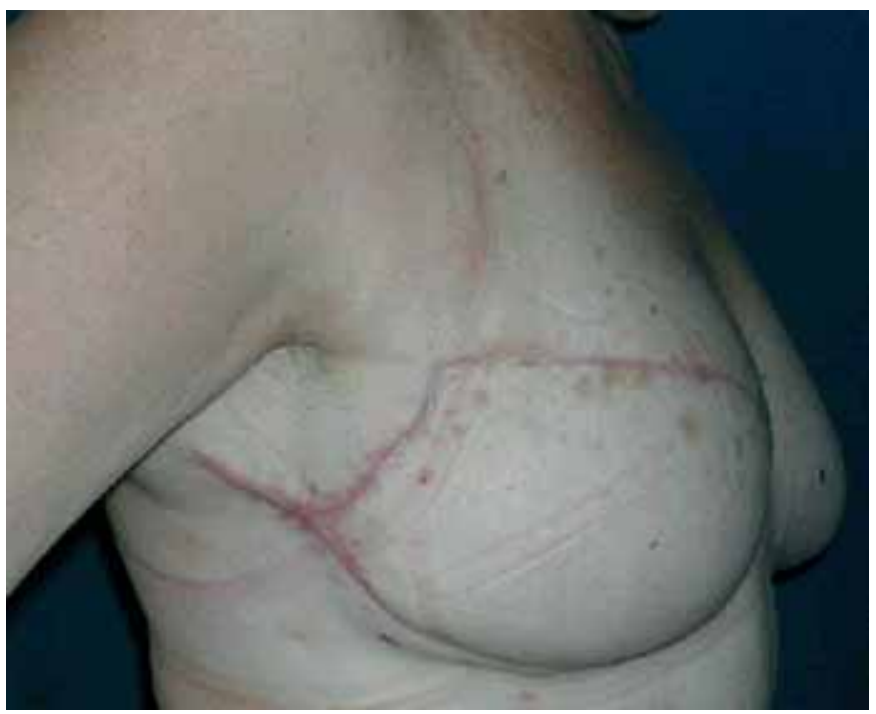

Fig. 12. Visión oblicua.

esta enfermedad y aporta un componente funcional importante que contribuye a la reincorporación de la paciente a su vida social y laboral con mayor comodidad y con mayores dosis de autoestima. Sin embargo, no debemos olvidar que el objetivo de este proceso es también estético, puesto que del aspecto definitivo que presente la mama dependerá el grado de satisfacción de la paciente y en virtud del mismo, se juzgará el éxito o fracaso del procedimiento en última instancia. Por lo tanto, en la búsqueda de este objetivo morfológico ha de practicarse una reconstrucción óptima.

Para conseguir el mejor resultado estético posible una vez tallado y extraído el colgajo, así como una vez practicada la microsutura, debemos plantearnos nuevas metas: Conseguir una mama estéticamente correcta; que la mama sea semejante a la mama contralateral; confeccionar una mama de contorno natural 


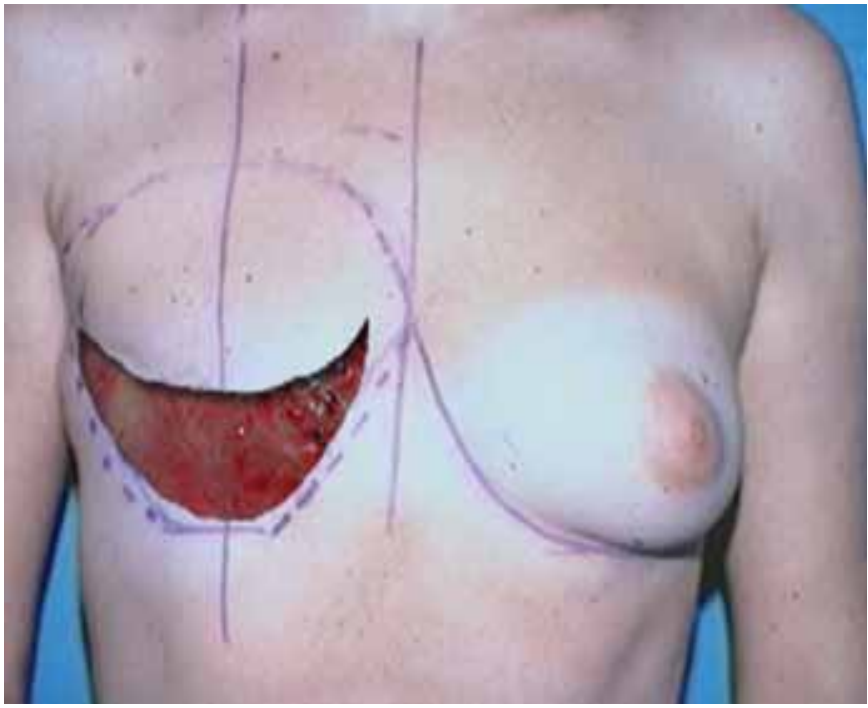

Fig. 15. Muesca en V frontal.

evitando efectos artificiales en el tórax de la paciente; conseguir un efecto de ptosis natural de la nueva mama; reproducir con la mayor fiabilidad posible las características morfológicas de la mama en cada cuadrante, en el surco submamario y en la cola y evitar en definitiva, la sensación de la paciente de portar una mama ajena a su integridad corporal, señal inequívoca de una mala remodelación.

Para conseguir nuestro objetivo hemos de valorar una serie de factores importantes. Cada uno de ellos se relacionará con un elemento primordial dentro del proceso reconstructivo, y así tendremos:

\section{Factores dependientes del colgajo:}

Homolateralidad: en nuestro medio se prefiere tallar el colgajo con pedículo homolateral al defecto, para conseguir así una mejor adaptación y orientación del mismo en lo que se refiere al aprovechamiento de sus áreas vasculares y a su ubicación en la zona receptora con el objetivo de recrear los cuadrantes y cola mamaria, concretamente porque de esta forma la zona III , tallada en forma de cuña se adapta muy satisfactoriamente a esta localización, sobre todo en el caso del colgajo TRAM, pero también de igual forma en el colgajo DIEP (Fig. 5 y 6).

Cicatriz umbilical: éste es un elemento de gran importancia y no exento de controversia en cuanto a su orientación. En relación directa con la homolateralidad del colgajo, en nuestra serie se prefiere la colocación de la cicatriz umbilical en posición superior, ya que en el proceso de remodelación esta zona puede desepidermizarse y ocultarse bajo el colgajo de piel torácica superior, quedando así disimulada (Fig. 7 y 8). Cuando no se puede llevar a cabo esta maniobra, es preciso cerrar correctamente el plano graso periumbilical para rellenar el espacio dejado

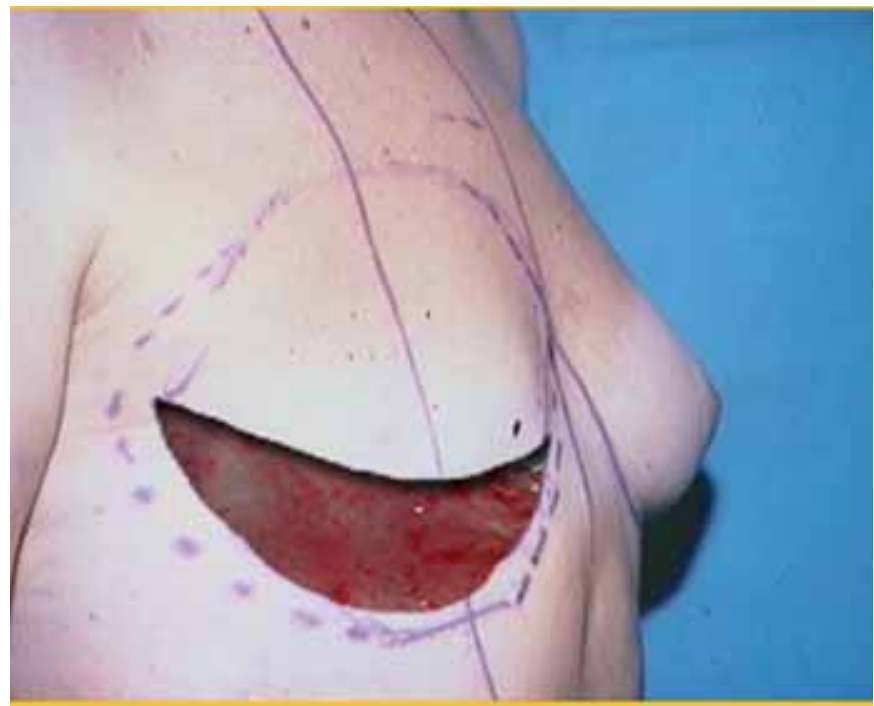

Fig. 16. Muesca en V lateral.

por el ombligo, cuya cicatriz tiende a deprimirse por falta de relleno.

Con respecto a la región umbilical, haremos un inciso para anotar que la disección de esta zona ha de ser muy cuidadosa, pues en ella se encuentra un gran número de perforantes.

Finalmente y si se decide la orientación en sentido caudal de la cicatriz, puede ser precisa su revisión en un segundo tiempo mediante la práctica de z-plastias para evitar la tendencia a la depresión. Situando la cicatriz con esta orientación, con frecuencia parte de ella queda finalmente oculta bajo el complejo teloareolar reconstruido (Fig.9).

Otro aspecto de importancia en relación con el colgajo es la porción del mismo que será dedicada a la remodelación de la cola mamaria. Esta zona anatómica ha de buscar la dirección de la axila proporcionando una continuidad desde el volumen principal de la mama. La recreación de la cola puede conseguirse de forma efectiva si se aprovecha la zona III tallada en forma de cuña, que aporta así un componente de naturalidad a la mama. Sin embargo, si aún así no se obtuviese el resultado deseado, siempre podrían practicarse z-plastias o v-plastias para mejorar el aspecto (Fig. 10).

\section{Factores dependientes de la zona receptora:}

Vasos receptores: La elección de los vasos receptores es de gran importancia en la reconstrucción con TRAM libre o DIEP. Inicialmente se realizaban las microsuturas en el pedículo tóracodorsal $(14,15)$ por su longitud adecuada, calibre aceptable y relativa constancia anatómica. Teníamos el inconveniente de que con ello se arriesgaba una segunda opción importante en caso de fallo de la reconstrucción (el colgajo de dorsal ancho) y de que es preciso asegurar la mayor longitud posible de pedículo donante. 


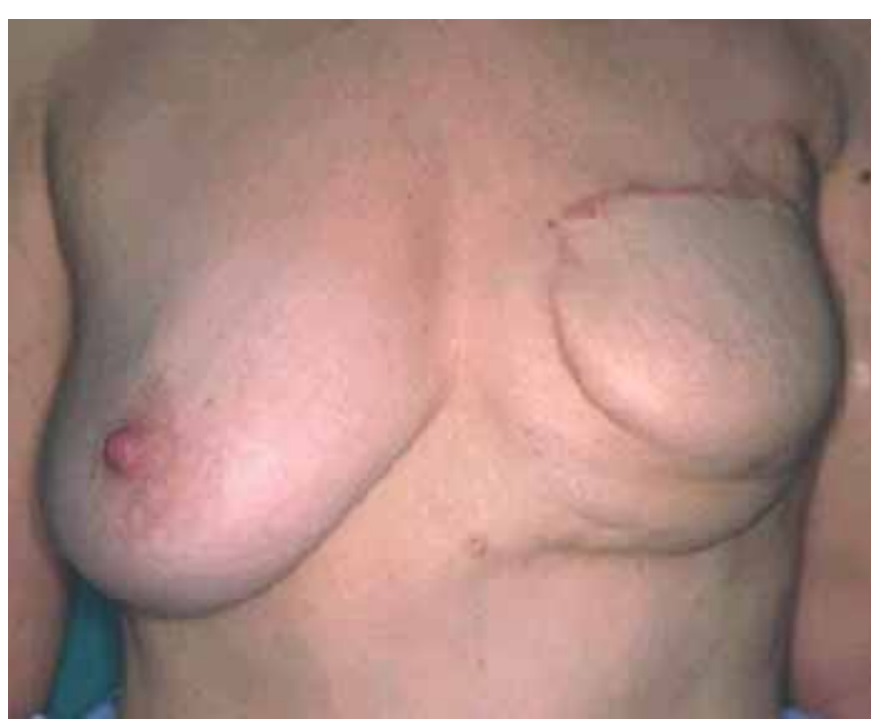

Fig. 13. Efecto “doble mama”. Visión lateral.

Hoy se preconiza que los vasos eferentes de elección para las anastomosis deben ser los mamarios internos (16) cuyo calibre y flujo son óptimos para soportar el colgajo y realizar la sutura, además de que al encontrarse tras la parrilla costal se hallan en una zona virgen en lo referente al tratamiento quirúrgico previo, si bien esto último podría cambiar ya que recientemente se está considerando la posibilidad de realizar linfadenectomías de la cadena mamaria interna. Las excursiones respiratorias que podrían en un principio dificultar la práctica de la microsutura no son lo suficientemente amplias en la región esternal como para interferirla. La presión negativa de la vena mamaria durante la inspiración favorece de forma muy notoria el flujo venoso. Favorable es así mismo que la arteria mamaria interna, al ser rama directa de la subclavia, presente presiones superiores, con menos tendencia al espasmo que en el caso de los vasos tóracodorsales.

Además el uso de este pedículo permite situar más medial el colgajo en el tórax, planteando menos problemas con la longitud del pedículo. Ello contribuye en definitiva a proporcionar una mayor maleabilidad del colgajo y una mejor adaptación al defecto.

Finalmente reseñaremos que al encontrarse el pedículo mamario bajo la cicatriz de mastectomía, la reconstrucción en el sitio receptor se practica en un sólo campo, el torácico, a diferencia de lo que ocurre si se eligen los vasos tóracodorsales, en cuyo caso se hace preciso abordar el campo axilar.

Otro de los factores dependientes de la zona receptora es la orientación y características de la cicatriz de mastectomía. Generalmente en nuestro medio suelen ser de trazo horizontal, siendo esta orientación la que en nuestra experiencia más facilita la remodelación del colgajo. Nuestra costumbre es proceder siempre al

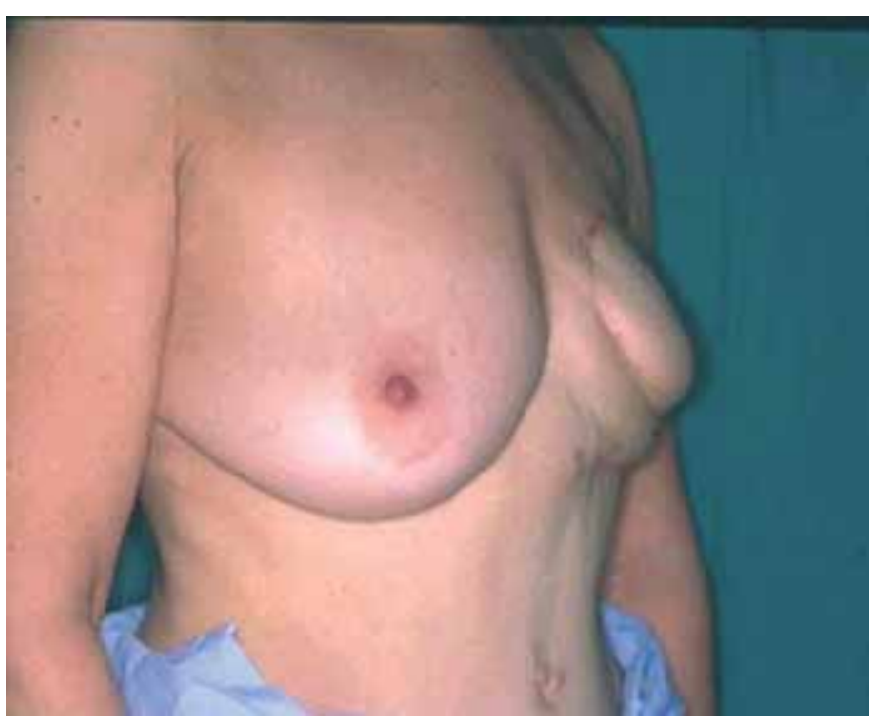

Fig. 14. Efecto "doble mama". Visión frontal.

análisis anatomopatológico de la misma tras su extirpación. A pesar de que en ningún caso se ha constatado la recidiva microscópica, lo seguimos haciendo de rutina.

Un aspecto importante a tener en consideración es el tratamiento de los colgajos torácicos de mastectomía, a fin de adaptarlos a la nueva configuración que tomará el área tras implantar el colgajo TRAM o DIEP. Nosotros preferimos llevar a cabo un gran despegamiento y resección del colgajo inferior desde la cicatriz hasta el nuevo surco submamario (Fig. $11 \mathrm{y}$ 12), conservando el pliegue natural de éste, en el caso de la reconstrucción inmediata, para que este espacio sea ocupado por el colgajo. La consistencia de la piel y del tejido celular subcutáneo que lo conforman, adoptará una curvatura elíptica recreando la ptosis natural de la mama. Además se ampliará la longitud de la cicatriz en este polo inferior evitando que el colgajo quede comprimido por la cicatriz de mastectomía y genere el indeseable y antiestético efecto en "doble mama "(Fig. 13 y 14).

Por el contrario tendemos a conservar la piel del colgajo torácico superior y si es posible, como se refirió anteriormente, se emplazará bajo él al colgajo TRAM o DIEP, previamente desepidermizado en su polo superior, con el fin de ocultar la cicatriz umbilical.

Pero como ocurre con el borde inferior de la cicatriz de mastectomía, también el borde superior puede llegar a comprimir al colgajo alterando nuestro resultado. Cuando esto ocurre, existen diversas formas de evitarlo, entre ellas cabe destacar la práctica de incisiones o descargas en $\mathrm{V}$ que según los casos pueden realizarse en posición central o lateral.

Si estas incisiones se realizan en posición central, hemos de tener en cuenta que serán más visibles y más difíciles de disimular, induciendo una muesca en 
la cicatriz del colgajo; por ello es preferible emplazarlas en posición lateral donde además contribuyen a generar un espacio ideal para el acoplamiento de la zona III en el intento de recrear la cola de la mama (Fig. 15 y 16).

Finalmente anotaremos que la desepidermización del polo superior del colgajo TRAM o DIEP para su acoplamiento no reviste ningún riesgo para su supervivencia, por lo que puede practicarse con toda seguridad. En ninguno de nuestros casos se produjo ninguna complicación relacionada con este procedimiento, ni compromiso de la vascularización.

Con respecto a las áreas vasculares del colgajo, las áreas más frecuentemente usadas en nuestra Unidad han sido la I completa, la III prácticamente completa y casi la totalidad de la zona II, desechando en la mayoría de los casos la zona IV, sobre todo en el DIEP, donde hemos encontrado una mayor incidencia de congestión venosa y déficit de irrigación. Con esta disposición y tallado del colgajo se obtienen resultados más que esperanzadores respetando la vascularización del mismo.

\section{Conclusiones}

Después de la práctica de 50 colgajos TRAM libres y DIEP (17), en el Servicio de Cirugía Plástica y Reconstructiva del Hospital Reina Sofía de Córdoba, estamos convencidos de que el proceso reconstructor tiene su culminación en la obtención de una nueva mama lo más natural posible; una mama que sirva para cumplir la función para la cual fue diseñada como parte integral del tratamiento del cáncer de mama.

Esa función no es otra que la de proporcionar a la paciente la satisfacción de recuperar un órgano de su cuerpo que forma parte integrante y primordial de su condición femenina y que influye sobremanera en la percepción de su propio cuerpo y en su capacidad de autoestima. La recuperación de este órgano recreado con sus propios tejidos favorece la reincorporación de la paciente a la vida social y laboral con una mayor seguridad y sin la necesidad de usar prótesis externas incómodas y antinaturales, ni tampoco implantes de silicona.

Los cirujanos plásticos hemos puesto gran énfasis en el desarrollo de las técnicas de autotrasplante microquirúrgico y las consideramos la intervención princeps en Cirugía Reconstructiva. No cabe duda de que el dominio de estas técnicas supone muchas horas de práctica y perfeccionamiento para familiarizarse con el tallado de los colgajos y con la realización de microsuturas cada vez más seguras y rápidas.

Sin embargo en el campo de la reconstrucción mamaria, el dominio de la técnica va un poco más allá y adquiere su talante más importante al final de la intervención, porque una vez concluido el desafío microquirúrgico llega el momento de poner en práctica la sensibilidad estética y el manejo de las formas para remodelar el colgajo y convertirlo en un mama.

Estos objetivos se pueden conseguir mediante la realización de una serie de procedimientos sencillos sobre el colgajo y sobre los tejidos del sitio receptor.

\section{Dirección del autor}

Dr. Félix T. Fidalgo Rodríguez.

C/Acije No 28, Nerva 21670, Huelva. España.

e-mail: felixfidalgo@yahoo.es

\section{Bibliografía}

1. Hartrampf CR, Scheflan M, Black PW.: "Breast reconstruction with a trasverse abdominal island flap". Plast Reconstr Surg 1982; 69: 216.

2. Holmstrom H.: "The free abdominoplasty flap and its use in breast reconstruction". Scand J Plast Surg 1979; 13: 423.

3. Maxwell GP, Falcone PA.: "Eighty-four consecutive breast reconstructions using a textured silicone tissue expander". Plast Reconstr Surg 1992; 89: 1022.

4. Kroll S.: "Why autologous tissue?". Clin Plast Surg 1998; 25: 135.

5. Robbins TH.: "Rectus abdominis myocuteneous flap for breast reconstruction. Aust N Z J Surg 1979; 85: 169

6. Galli A, Berrino P,Rainero ML, Santi P.: "Transcription of miocuteneous flaps in breast reconstruction following radical mastectomy: latissimus dorsi vs. Rectus abdominis flap". Tumori 1988; 74 : 195.

7. Cavadas PC, de la Fuente MC.: "Reconstrucción mamaria diferida con colgajo libre de perforantes de arteria epigástrica inferior profunda (DIEP). Experiencia en 13 casos". Cir Plas Iberolatinoam 2000; 26: 287.

8. Nahabedian MY, Momen B, Galdino G, Manson PN.: "Breast Reconstruction with the free TRAM or DIEP flap: patient selection, choice of flap, and outcome". Plast Reconstr Surg. 2002;110(2):466; discussion 476.

9. Grotting JC, Urist MM, Maddox WA, Vasconez LO.: "Conventional Tram flap versus free microsurgical Tram flap for inmediate breast reconstruction". Plast Reconstr Surg 1989; 83: 828.

10. Gherardini G, Arnander C, Gylbert L, Wickman M.: "Pedicled compared with free transverse rectus abdominis myocutaneous flaps in breast reconstruction". Scand J Plast Reconstr Hand Surg 1994; 28: 69.

11. Cabrera Sánchez E, Redondo Camacho A, Dean Ferrer A et al.: "Satisfacción en pacientes con reconstrucción mamaria con colgajo DIEP". Cir Plas. Iberolatinoam. 2006, 32 (3): 169.

12. Taylor GI, Palmer JH.: "The vascular territories (angiosomes) of the body: Experimental study and clinical applications". Br J Plast Surg 1987; 40: 113 .

13. Boiyd JB, Taylor GI, Corlett RJ.: "The vascular territories of the superior epigastric and deep inferior epigastric system". Plast Reconstr Surg 1984; 73: 1.

14. Feng LJ.: "Recipient vessels in free-flap breast reconstruction: a study of the internal mammary and thoracodorsal vessels". Plast Reconstr Surg. 1997 ;99(2):405.

15. Serletti JM, Moran SL, Orlando GS, Fox I.: "Thoracodorsal vessels as recipient vessels for the free TRAM flap in delayed breast reconstruction". Plast Reconstr Surg. 1999;104(6):1649.

16. Majumder S, Batchelor AG.: "Internal mammary vessels as recipients for free TRAM breast reconstruction: aesthetic and functional considerations".Br J Plast Surg. 1999;52(4):286.

17. Rioja L, Redondo A, Garcia E, de Haro J.: "Reconstrucción mamaria con colgajo TRAM libre". Cir Plas Iberolatinoam 2002; 28: 39 . 


\title{
Comentario al trabajo uRemodelaciones en colgajos TRAM libres y DIEP॥
}

\author{
Dr. Luis O. Vasconez. Profesor de Cirugía. J efe de la División de Cirugía Plástica. \\ Universidad de Alabama. Birmingham, Alabama. EEUU.
}

La reconstrucción mamaria ha evolucionado vertiginosamente, hasta el punto de que las pacientes no sólo exigen simetría con la mama opuesta, sino también una mejoría estética de las dos mamas. No podemos sentirnos satisfechos con que el colgajo haya sobrevivido, sino que hay que hacer reconstrucciones simétricas, sin complicaciones y dejando mamas cónicas, juveniles y de una talla que se corresponda con el cuerpo de la paciente. Todo esto lo podemos conseguir gracias a la seguridad y versatilidad del colgajo TRAM, ya sea libre o convencional.

Existen tres factores esenciales para una reconstrucción mamaria simétrica y satisfactoria: el surco inframamario, la proyección de la mama y la caída-ptosis de la misma. Me referiré rápidamente a cada factor.

El surco inframamario indica el borde inferior de la mama normal, o en el caso del TRAM, el borde inferior del colgajo. En el caso de una reconstrucción con implante, el surco submamario es la cápsula en la parte inferior del implante. Por eso, si la reconstrucción es inmediata, marcamos con suturas el surco submamario antes de la mastectomía porque el cirujano oncológico no necesita disecar por debajo de éste. En la reconstrucción diferida, marcamos el surco en la mama normal y lo extendemos a la superficie plana del lado de la mastectomía. Hay que recordar que la mama normal sólo llega hasta la línea axilar anterior, por lo que hay que evitar poner el colgajo más lateralmente.

En cuanto a la reducción mamaria del lado opuesto, si se hace con pedículo inferior no alterará el surco submamario; en cambio, si empleamos el método de pedículo súperomedial (Hall-Findlay), sí se puede subir dicho surco si se reseca el borde inferior de la mama.

Entendemos por proyección mamaria el diámetro transversal desde el esternón hasta la línea axilar anterior sobre la superficie curva de la mama. Para aumentar dicha proyección, particularmente cuando existe una mastectomía de incisión transversal, hay que zigzaguear la incisión para aumentar el diámetro transversal. Igualmente se puede conificar el colgajo libre para lograr mayor proyección.

La ptosis está representada por el meridiano medido desde la clavícula sobre la superficie curva de la mama hasta el surco inframamario. Para recrearla necesitamos un colgajo ancho, que llene el vacío debajo de la clavícula y caiga por debajo del surco inframamario.

Los autores del artículo son conscientes del objetivo estético de la reconstrucción mamaria y nos indican normas correctas para obtener un resultado simétrico y estético. Me permito indicar varios puntos de gran importancia al respecto.

Casi siempre la anastomosis vascular se hace a los vasos de la mamaria interna, especialmente en casos de reconstrucción diferida. La mamaria interna es más fácil, no se necesita rotar al paciente y permite que el colgajo llegue al surco submamario; además, el colgajo se puede doblar para darle más proyección a la mama. En cambio, si escogemos los vasos tóracodorsales, por lo general hay que disecar sobre tejido cicatricial y a veces irradiado.

Preferimos modificar la mama opuesta, ya sea mediante reducción o mastopexia, en el mismo tiempo quirúrgico de la reconstrucción. Esto nos llevará un poco más de tiempo, pero creo que es más fácil obtener así simetría, que se comprueba sentando al paciente durante la intervención. De esta forma, solo nos quedan los toques finales, que haremos en el tiempo quirúrgico de la reconstrucción del complejo areolapezón.

La mayoría de nuestras reconstrucciones son inmediatas, con ventajas para la paciente y facilitando la simetría, especialmente ahora que la mastectomía se practica por la vía periareolar preservando la piel intacta de la mama. Solo falta llenar el bolsillo de piel que queda con el colgajo TRAM. Si está indicada la reducción de la mama contralateral, se reduce el bolsillo de piel por vía periareolar haciendo el fruncido necesario. Desde luego, esto no es aconsejable si la paciente va a recibir radiación. Curiosamente, el $78 \%$ de las pacientes que presentan los autores han recibido radioterapia, lo que parece excesivo en vista de la práctica actual.

La reconstrucción areolar la hacemos mediante tatuaje, evitando tomar injerto de piel de la ingle que, como los autores dicen, no da un buen resultado.

Creo que hay poca diferencia entre el colgajo TRAM libre en el que se incluyen unos $3 \mathrm{~cm}$. de músculo, y el DIEP, que es más difícil de disecar y necesita mayor experiencia clínica, depende del número de venas acompañantes y toma más tiempo quirúrgico. Reconozco que el DIEP está de moda, pero no estoy convencido de sus ventajas.

Desde el punto de vista logístico, es necesario formar dos equipos bien entrenados y flexibles; si se hace una reconstrucción inmediata, son necesarios dos campos operatorios y dos equipos separados: el oncológico y el reconstructivo. En la reconstrucción diferida, un equipo hace la microcirugía, el otro cierra el abdomen y cualquiera de los dos hace la reducción de la mama opuesta. La ventaja adicional es que hay varios microcirujanos para que no intervenga el factor cansancio. Los colgajos mueren en la sala de operaciones y el microcirujano sabe con certeza, casi siempre, cuándo va a ir bien el colgajo y cuándo es preferible repetir la microanastomosis.

Por último, el diseño del colgajo casi siempre lo hacemos a nivel del ombligo. La incisión superior preserva el ombligo, porque la perforante mayor está a unos $2 \mathrm{~cm}$. por debajo del mismo. De esta forma, el colgajo es más fácil de despitelizar y proyectar. 


\section{Respuesta al comentario del Dr. Luis 0. Vasconez}

\section{Dr. Félix T. Fidalgo}

Ante todo mi agradecimiento más sincero al comité científico por la deferencia que ha tenido a la hora de publicar este trabajo y por supuesto al Dr Vasconez que ha tenido la amabilidad de elaborar el comentario al mismo. Siempre es un honor y un privilegio contar con la opinión de renombrados profesionales en el campo de la Cirugía Reconstructiva.

Nos complace comprobar que en la mayor parte de su exposición el Dr Vasconez coincide en la concepción de que la reconstrucción mamaria postmastectomía va mucho mas allá del reto microquirúrgico; igualmente coincidimos con él en la mayor parte de los factores que enumera como fundamentales para conseguir un buen resultado morfológico.

En lo referente a la reconstrucción inmediata tengo que decir que nos encontramos totalmente a favor, pero que en nuestro centro la organización de la asistencia no nos ha permitido ofrecer a las pacientes una asistencia totalmente integral hasta hace muy poco, coincidiendo con la creación de una Unidad de Patología Mamaria multidisciplinar. Es por eso que en nuestra serie inicial la mayor parte de las reconstrucciones fueron diferidas, es decir realizadas cuando ya concluyó todo el tratamiento oncológico, realizado quirúrgicamente por cirujanos generales y médicamente por oncólogos médicos y radioterapeutas. Afortunadamente esto ha cambiado $\mathrm{y}$ ahora la colaboración es estrecha.

Del mismo modo, uno de los criterios de selección que seguimos inicialmente para la realización de la reconstrucción microquirúrgica fue precisamente la existencia de signos de radiodermitis crónica, circunstancia que nos obligaba a usar tejidos autólogos a la hora de realizar la reconstrucción. Esta es la causa de nuestro alto porcentaje de pacientes tratadas con radioterapia, pero insisto, realizada previamente a la cirugía reconstructiva. Nuestra actitud actualmente es la de evitar la reconstrucción inmediata si la paciente va a recibir radioterapia; esto se puede predecir gracias a la biopsia del ganglio centinela que se practica de rutina en nuestro centro, y tiene como justificación los peores resultados que hemos observado a largo plazo en la estructura de colgajos expuestos a radiación.

Además, dado el tamaño de nuestra Unidad no podíamos ofrecer a todas la pacientes la opción de la reconstrucción inmediata microquirúrgica, circunstancia que hoy se mantiene por cuestiones meramente logísticas que afectan a un Servicio pequeño como el nuestro, de tal forma que en un porcentaje importante de pacientes mastectomizadas se opta por la reconstrucción con implantes, sobre todo en la reconstrucción inmediata. Comprendo la poca solidez científica de estas afirmaciones pero la falta de personal y medios nos condiciona a adoptar esta actitud.

La opción de elegir entre TRAM y DIEP es algo que sigue causando controversia, es cierto que el DIEP consume más recursos, siendo el resultado semejante al del TRAM conservador de músculo, no obstante nuestra tendencia ha sido la de evolucionar hacia la realización del DIEP, no porque esté de moda o porque sea un paso técnico a superar que ensalce nuestro ego quirúrgico, sino porque consideramos que la concepción anatómica del colgajo de perforantes supone un avance en cuanto a la reducción de la morbilidad en la pared abdominal. En cualquier caso tengo que añadir que inicialmente programamos un DIEP pero dependiendo de las perforantes que encontremos podemos reconvertir a un TRAM si lo consideramos oportuno.

Agradezco al Dr Vasconez las anotaciones técnicas que nos regala en su comentario y que son de gran valor pues sirven, como espero sirvan las nuestras, para ampliar el arsenal de maniobras útiles a la hora de conseguir el éxito en este tipo de intervenciones. De entre ellas añadiré que ya estamos iniciando la modificación de la mama sana en el mismo acto gracias a la reducción de los tiempos quirúrgicos en la reconstrucción propiamente dicha. Del mismo modo hemos adquirido un dispositivo para realizar la micropigmentación de las areolas y esperamos abandonar en breve la practica de injertos cutáneos.

Con respecto a los vasos receptores los más usados actualmente son los mamarios, pero no nos da miedo la radioterapia en la axila si tenemos que usar los tóracodorsales por cualquier razón; lo que nos da miedo es la calidad del cirujano que practicó la linfadenectomía axilar. En la misma línea diré, que por ahora no hemos podido influir en la actitud de los cirujanos generales para que realicen mastectomías conservadoras de piel periareolares, aunque seguiremos insistiendo; prefieren seguir realizando la mastectomía radical modificada.

Finalmente quiero expresar una opinión personal que creo que muchos compañeros compartirán y es que partiendo de la premisa de que nuestro objetivo es la consecución del mejor resultado posible y que para ello precisamos un sustrato lo más adecuado posible, lo ideal, desde mi punto de vista, seria que todo el proceso quirúrgico, tanto oncológico como reconstructivo lo practicásemos los cirujanos plásticos. 